\title{
Effect of Niceritrol on Lipid Metabolism of Aorta in Atherosclerotic Rats
}

\author{
Kohji Shirai, Yoh Ishikawa, Toshio Nishide, Norihiro \\ Sasaki, Shunichi Murano, Akira Sato, Nobuo \\ Matsuoka, Yasushi Saito and Sho Yoshida \\ Second Department of Internal Medicine, School of \\ Medicine, Chiba University, Chiba 280
}

Shirai, K., Ishikawa, Y., Nishide, T., Sasaki, N., Murano, S., Sato, A., Matsuoka, N., Saito, Y. and Yoshida, S. Effect of Niceritrol on Lipid Metabolism of Aorta in Atherosclerotic Rats. Tohoku J. exp. Med., 1984, 143(2), 231-238 Atherosclerotic lesions were formed in the aorta of rats given a high cholesterol diet containing propylthiouracil (PTU) and vitamin D2 (atherogenic diet) for 8 weeks. The effects of niceritrol (pentaerythritol tetranicotinate), which lower the plasma lipid level, on lipid metabolism in the arterial wall of the atherosclerotic rats were studied. Niceritrol significantly decreased the plasma cholesterol level of atherosclerotic rats, which was $823 \mathrm{mg} / 100 \mathrm{ml}$, or about ten times that of control rats. On treatment with niceritrol, the cholesterol level was reduced most in the very low density lipoprotein (VLDL) fraction $(\mathrm{d}<1.006)$. Heparin-releasable lipoprotein lipase activity in epididymal adipose tissue, lipoprotein lipase activity in post-heparin plasma, and VLDL-triolein hydrolyzing activity in adipose tissue stromal vessels were all higher in niceritrol-treated atherosclerotic rats. Of the enzymes in the arterial wall concerned with cholesterol ester metabolism, acid cholesterol esterase activity was decreased in atherosclerotic rats, while niceritrol treatment increased this activity. The ratio of acyl-CoA cholesterol acyltransferase activity (ACAT) to neutral cholesterol esterase activity was higher in atherosclerotic rats than in control rats, but was lower in niceritrol-treated rats than in atherosclerotic rats. From these results, it is concluded that niceritrol modifies enzyme activities in such a way as to reduce the cholesterol ester content of the arterial wall and lower plasm VLDL and LDL cholesterol levels.

atherosclerosis ; niceritrol ; cholesterol ester ; arterial wall ; lipoprotein lipase

The serum cholesterol level is correlated with the incidence of coronary heart disease (Olsson et al. 1974), and reduction of high plasma cholesterol levels is expected to reduce atherosclerotic lesions. Niceritrol has been shown in clinical studies to lower the level of plasma lipids (Sigroth 1968). It is also known that not only plasma level of cholesterol, but also the lipid metabolism in the arterial wall is involved in the formation of atheromas.

Rats are known to be insusceptible to atherosclerosis induced by administration of a high cholesterol diet (Kritchevsky and Kothari 1978). Moreover administration of vitamin $\mathrm{D}_{2}$ and an antithyroid agent to rats in addition to a high

Received for publication, October 18, 1983. 
cholesterol diet, results in formation of atheromatous lesions and the enzyme activities concerned with cholesterol ester metabolism, such as acid and neutral cholesterol esterase and acyl-CoA cholesterol acyltransferase (ACAT) in the arterial wall, are deranged in such a way as to promote the deposition of cholesterol ester in the arterial wall (Morisaki et al. 1982).

This paper reports studies on the effects of niceritrol on plasma lipid levels, lipoprotein lipase activities that are known to be involved in catabolism of very low density lipoprotein, and enzyme activities in the aorta concerned with lipid metabolism, such as acid and neutral cholesterol esterase, and ACAT.

\section{Materials and Methods}

Animals and experimental conditions

Male Wistar-King Strain rats, weighing 140-160 g were divided into 3 groups and were given the following diets : Group I- control diet consisting of normal chow diet (Oriental Kobo Co, Ltd,, Tokyo) supplemented with $0.2 \%$ propylthiouracil. Group II —atherogenic diet consisting of control diet supplemented with $0.2 \%$ propylthiouracil, $1 \%$ cholesterol and $0.5 \%$ cholic acid. Group III - niceritrol-containing diet consisting of atherogenic diet supplemented with $0.5 \%$ niceritrol. The normal chow diet contained $53.0 \%$ carbohydrate, $24,1 \%$ protein, $4.6 \%$ fat, $7.0 \%$ minerals, $4.2 \%$ fiber, and $7.0 \%$ water. Rats were given $1 \times$ $10^{5}$ units of vitamin $\mathrm{D}_{2}$ (Sigma) per day for the first 4 days, and then $20 \mathrm{~g}$ per day for 8 weeks. Niceritrol was provided by Sanwa Chemical Co., Nagoya.

\section{Lipoprotein analysis}

Serum lipoprotein was fractionated in an ultracentrifuge (Beckman 52) with a Beckman LpTi 42 rotor. Serum itself $(\mathrm{d}=1.006)$, and serum adjusted to a density of 1.063 with potassium bromide were centrifuged at $41,000 \mathrm{rpm}$ for 3 hours. The lipid contents of the bottom fractions of each, and that of the original whole serum were determined. The lipid content of the bottom fraction of $\mathrm{d}=1.063$ was that of high density lipoproteins (HDL). The lipid content of the fraction responsible for the difference in the fraction of $d=1.063$ and that of $d=1.006$ was that of the value of low density lipoproteins (LDL). Similarly the lipid in the very low density lipoprotein (VLDL) fraction was responsible for the difference in the values for the HDL and LDL fractions from that of total lipid. Serum total cholesterol was assayed with cholesterol esterase, cholesterol oxidase and peroxidase. Serum triglyceride was measured enzymatically with lipoprotein lipase, glycerol dehydrogenase and diaphorase. Serum phospholipid enzymatically with phospholipase D and choline oxidase.

\section{Preparation of enzyme solution from arterial wall}

Rats were starved for $24 \mathrm{~h}$ and then decapitated. The aorta from the aortic arch to the bifurcation was removed and washed in cold $0.25 \mathrm{M}$ sucrose-5 mM Tris-HCl buffer ( $\mathrm{pH} 7.4$ ). The adventitia was carefully removed and then the aorta was cut up and homogenized in a iscotron (Nichion Co., Ltd., Tokyo). The homogenate was centrifuged at $800 \times \mathrm{g}$ for 5 min, and the resultant supernatant was used as the enzyme solution. All these procedures were performed at $4^{\circ} \mathrm{C}$.

\section{Cholesterol esterase activity}

A sonicated mixture of cholesterol oleate, cholesterol $\left[1-{ }^{14} \mathrm{C}\right]$ oleate and phosphatidylcholine was used as substrate. Acid cholesterol esterase was measured at $\mathrm{pH} 4.5$, and neutral cholesterol esterase was at $\mathrm{pH}$ 7.5. Details of the methods were reported previously 
(Shinomiya et al. 1979).

\section{Acyl-CoA : cholesterol acyltransferase activity (ACAT)}

The reaction mixture, consisting of $50 \mu \mathrm{M}\left[1-{ }^{14} \mathrm{C}\right]$ palmitoyl-CoA, $2 \mathrm{mM}$ dithiothreitol, $1 \%$ albumin, $100 \mathrm{mM}$ potassium phosphate buffer ( $\mathrm{pH} 7.4$ ), and enzyme solution in a final volume of $0.25 \mathrm{ml}$, was incubated for $15 \mathrm{~min}$ at $37^{\circ} \mathrm{C}$, and the reaction was stopped by adding $2 \mathrm{ml}$ of chloroform-methanol $(2: 1$, by vol). Lipids were extracted by the method of Folch et al. (1957), and the $\left[1{ }^{-14} \mathrm{C}\right]$ cholesterol palmitate formed was separated by thin layer chromatography by the method of Skipski et al. (1965). The optimal $\mathrm{pH}$ was $\mathrm{pH}$ 7.5-8.0.

\section{Lipoprotein lipase activity}

The lipoprotein lipase (LPL) activities of adipose tissue and post-heparin plasma were measured using tri $\left[1{ }^{14} \mathrm{C}\right]$ oleoyl glycerol emulsified with Triton $\mathrm{X}-100$. Minced epididymal adipose tissue $(0.5 \mathrm{~g})$ was incubated with $50 \mu \mathrm{g} / \mathrm{ml}$ of heparin in $5 \mathrm{ml}$ of $0.9 \% \mathrm{NaCl}$ and 10 $\mathrm{mM}$ Tris- $\mathrm{HCl} \mathrm{pH} 7.4$ for $20 \mathrm{~min}$ at $37^{\circ} \mathrm{C}$, and the supernatant obtained by centrifugation at $1,500 \mathrm{rpm}$ for $5 \mathrm{~min}$ was used as enzyme. Post-heparin plasma was prepared by injecting $100 \mu \mathrm{g}$ of heparin into rats. The procedure for enzyme assay and extraction of released fatty acid were described previously (Matsuoka et al. 1980). Hepatic lipase activity was assayed in the presence of $1 \mathrm{M} \mathrm{NaCl}$. The LPL activity in post-heparin plasma was calculated as the difference between the values for hepatic lipase activity and total lipase activity.

\section{Hydrolysis of very low density lipoprotein-triolein}

VLDL-triolein hydrolysis was determined as described previously (Matsuoka et al. 1981). Briefly, VLDL was labeled with tri $\left[1-{ }^{14} \mathrm{C}\right]$ oleoyl glycerol using dimethylsulfoxide by the method of Fielding (1979).

The reaction mixture contained $300 \mu \mathrm{g}$ of triolein of tri $\left[1-{ }^{14} \mathrm{C}\right]$ oleoyl glycerol-labeled VLDL, $2.0 \%$ bovine serum albumin, $50 \mathrm{mM}$ Tris- $\mathrm{HCl}, \mathrm{pH}$ 7.4, and enzyme in a final volume of $250 \mu$ l. Incubation was performed for $60 \mathrm{~min}$, and the released fatty acids were determined by the method of Belfrage and Vaughan (1969).

\section{Results}

\section{Body and tissue weight}

The average body weight of rats in Group III was lower than that of rats in Group II, as shown in Table 1. The liver weight of Group II was significantly more than that of Group I, and that of Group III was lower than that of Group II. The adipose tissue weight of rats in Group III was lower than those of rats

Table 1. Effect of Niceritrol on Body and Tissue Weights

\begin{tabular}{llcl}
\hline & Group I & Group II & Group III \\
\hline & $(n=6)$ & $(n=6)$ & $(n=10)$ \\
Body & $159 \pm 12$ & $158 \pm 11 \dagger$ & $134 \pm 8 \dagger$ \\
Liver & $5.5 \pm 0.5 \ddagger$ & $10.6 \pm 1.4 \ddagger$ & $9.4 \pm 0.9^{*}$ \\
Adipose Tissue & $1.3 \pm 0.2$ & $1.1 \pm 0.2^{*}$ & $0.9 \pm 0.1^{*}$
\end{tabular}

Mean \pm S.D.

${ }^{*} p<0.05, \dagger p<0.01, \ddagger p<0.005$. 
in Groups I and II.

\section{Serum lipid content}

The serum total cholesterol and phospholipid levels in Group II were significantly higher than those in Group I, as shown in Table 2. In Group III, the cholesterol and phospholipid levels were significantly lower than those in Group II. The triglyceride level in the three groups were not significantly different. The VLDL cholesterol level was much higher in Group II than in Group I and was less in Group III than in Group II, as shown in Table 3. The LDL cholesterol level was also higher in Group II than in Group I, and was lower in Group III than in Group II. The HDL cholesterol levels in the three groups were not significantly different.

TABLE 2. Effect of Niceritrol on Serum Concentration of Lipids

\begin{tabular}{lllc}
\hline \multicolumn{1}{c}{ Lipid } & Group I & \multicolumn{1}{c}{ Group II } & Group III \\
\hline & $(n=6)$ & $(n=6)$ & $(n=10)$ \\
Total cholesterol & $85 \pm 11 \ddagger$ & $823 \pm 256 \ddagger \dagger$ & $468 \pm 106 \dagger$ \\
Triglyceride & $103 \pm 16$ & $112 \pm 25$ & $91 \pm 13$ \\
Phospholipid & $114 \pm 14 \ddagger$ & $246 \pm 69 \ddagger^{*}$ & $187 \pm 24^{*}$ \\
\hline
\end{tabular}

Mean \pm S.D. $\mathrm{mg} / 100 \mathrm{ml}$.

* $p<0.05, \dagger p<0.01, \ddagger p<0.005$.

TABLE 3. Effect of Niceritrol on Lipoprotein Cholesterol

\begin{tabular}{lccc}
\hline \multicolumn{1}{c}{ Lipoprotein } & Group I & Group II & Group III \\
\hline & $(n=6)$ & $(n=6)$ & $(n=10)$ \\
Very low density lipoprotein & $6 \pm 0.6 \dagger$ & $532 \pm 199 \dagger$ & $257 \pm 81 \dagger$ \\
Low density lipoprotein & $31 \pm 6 \dagger$ & $241 \pm 53 \ddagger$ & $151 \pm 53 \dagger$ \\
High density lipoprotein & $48 \pm 5$ & $49 \pm 8$ & $51 \pm 14$ \\
\hline
\end{tabular}

Mean \pm S.D. $\mathrm{mg} / 100 \mathrm{ml}$.

* $p<0.05, \dagger p<0.01$.

\section{Lipoprotein lipase activity in adipose tissue}

The heparin-releasable LPL activity in adipose tissue was similar in Group I and II, as shown in Fig. 1, but that in Group III was significantly higher.

\section{Post-heparin plasma lipolytic activity}

The LPL activity of post-heparin plasma was higher in Group III than in Group I or Group II, as shown in Fig. 2. The hepatic lipase activities of the three groups were not significantly different. 


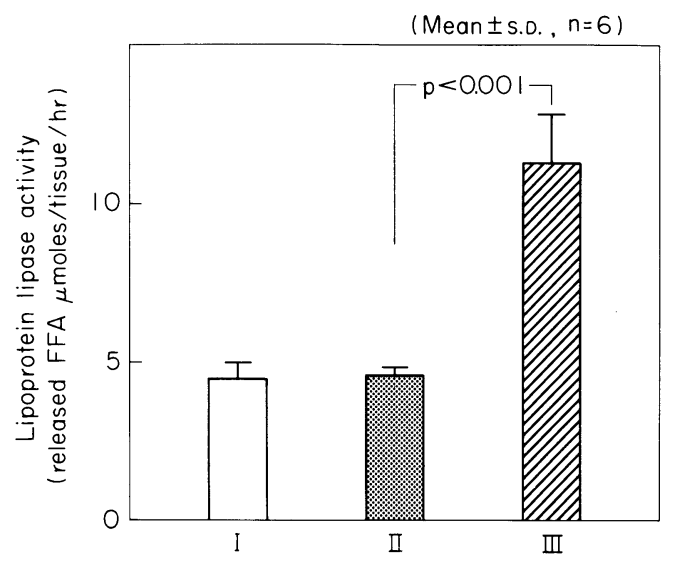

Fig. 1. Effect of niceritrol on adipose tissue lipoprotein lipase.

I : Control diet group.

II : Atherogenic diet group.

III : Niceritrol-containing diet group.

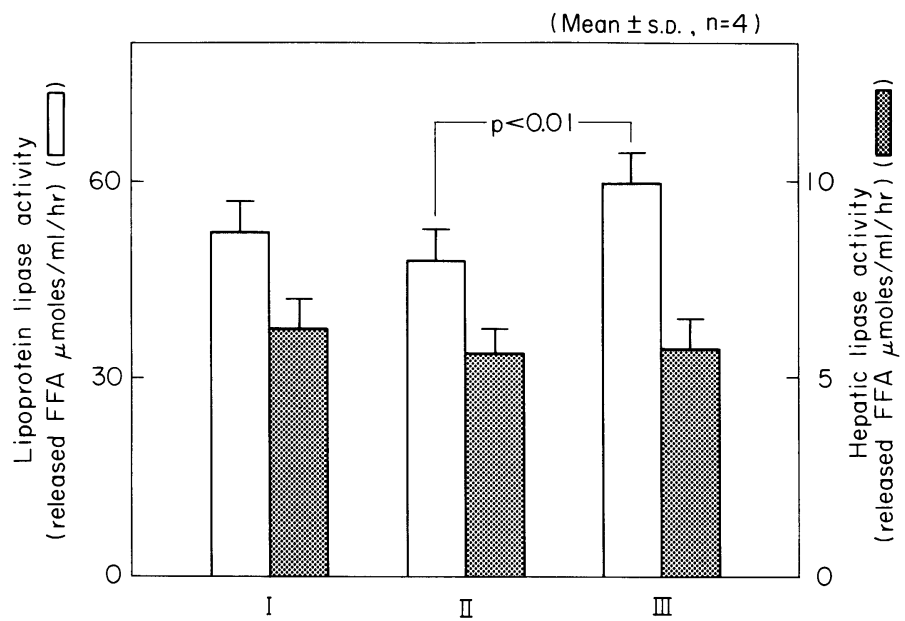

Fig. 2. Effect of niceritrol on post-heparin plasma lipolytic activity.

I : Control diet group.

II : Atherogenic diet group.

III : Niceritrol-containing diet group.

\section{VLDL-triolein hydrolysis by adipose stromal vessels}

As shown in Fig. 3, VLDL-triolein hydrolysis by adipose stromal vessels was significantly lower in Group II than in Group I and that in Group III was significantly higher than that in Group II.

Enzyme activities in the arterial wall

As shown in Table 4, acid cholesterol esterase and neutral cholesterol esterase 


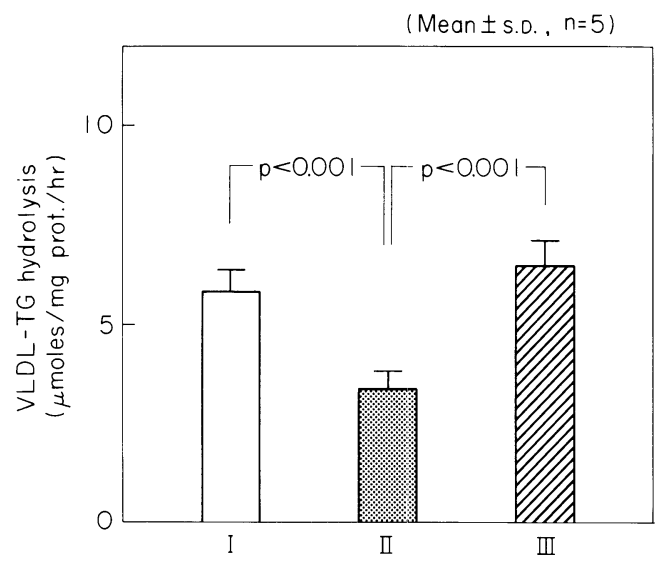

Fig. 3. Effect of niceritrol on VLDL-TG hydrolysis in adipose tissue vessels.

I : Control diet group.

II : Atherogenic diet group.

III : Niceritrol-containing diet group.

Table 4. Effect of Niceritrol on Lipid Metabolism in the Arterial Wall

\begin{tabular}{lccc}
\hline \multicolumn{1}{c}{ Enzyme } & Group I & Group II & Group III \\
\hline $\begin{array}{l}\text { Acid cholesterol esterase } \\
\text { (nmoles/mg prot/hr) }\end{array}$ & $2.98 \pm 0.29 \dagger$ & $2.63 \pm 0.28 \dagger$ & $3.45 \pm 0.6 \dagger$ \\
$\begin{array}{l}\text { Neutral cholesterol esterase } \\
\text { (nmoles/mg prot/hr) }\end{array}$ & $5.12 \pm 1.56^{*}$ & $3.99 \pm 0.55^{* *}$ & $4.60 \pm 1.89^{*}$ \\
ACAT (pmoles/mg prot/hr) & $12.4 \pm 4.7^{*}$ & $18.8 \pm 6.2^{*}$ & $19.0 \pm 6.2$ \\
\hline
\end{tabular}

Mean \pm S.D. $n=6$.

* $p<0.01, \dagger p<0.05$.

were lower in Group II than in Group I and were higher in Group III than in Group II. ACAT activity was significantly higher in Groups II and III than in Group I, but was similar in Groups II and III.

\section{Discussion}

In this work high cholesterol diet containing the antithyroid agent propylthiouracil induced severe hypercholesterolemia and atherosclerotic lesions, as reported previously (Morisaki et al. 1982). The addition of niceritrol to' this diet reduced the plasma cholesterol levels by $45 \%$. The mechanism of this effect of niceritrol in lowering the plasma lipid level is not well understood. The decreased liver weight and lipid content observed in rat treated with niceritrol may be due to low lipid synthesis or low cholesterol absorption from the intestine. Niceritrol is a derivative of nicotinic acid, and the latter is known to inhibit cholesterol synthesis in the liver. It is unlikely that niceritrol inhibits secretion of VLDL from the liver, but further studies are necessary on its effect in the liver.

Lipoprotein lipase is believed to facilitate the removal of VLDL triglyceride 
from the blood. In rats treated with niceritrol, the LPL activity released from adipose tissue by heparin and LPL in post-heparin plasma were increased. Furthermore the decreased VLDL-triolein hydrolysis by adipose stromal vessels of atherosclerotic rats was restored to the control level by niceritrol treatment. These results suggest that catabolism of VLDL is enhanced by niceritrol administration. In other words, one mechanism by which niceritrol lowers the triglyceride level is by increasing LPL activity. LPL activity in adipose tissue is also reported to be increased by administration of nicotinic acid (Nikkila 1971).

LDL cholesterol is thought to be taken up by LDL receptor on the cell surface and hydrolyzed by acid cholesterol esterase in lysosomes. The released cholesterol is then thought to be transferred to microsomes and reesterified by ACAT, and the resulting cholesterol ester is then hydrolyzed by neutral cholesterol esterase, and released cholesterol is removed from the cell membrane by high density lipoproteins (Tall and Small 1980). On the basis of these reactions in cholesterol metabolism in the cell, decreases in acid cholesterol esterase and the ratio of neutral cholesterol esterase activity to ACAT activity should cause accumulation of cholesterol ester in the cells. In atherosclerotic rats, acid cholesterol esterase activity and the ratio of neutral cholesterol esterase to ACAT activity (from 0.41 to 0.21 ) are in fact decreased, suggesting that lipid metabolism in atherosclerotic rats promotes the accumulation of cholesterol in the cells. These results are consistent with a previous report from this laboratory (Morisaki et al. 1982). In niceritrol-treated rats, acid CEase increased, and the ratio of CEase to ACAT increased (from 0.21 to 0.24 ). These changes should reduce accumulation of cholesterol ester in the cells. It is unknown whether these changes in enzyme activities were due to a direct effect of niceritrol on the arterial wall or an indirect effect through the lowered lipid levels. These results indicate that administration of niceritrol to rats with cholesterol-induced atherosclerosis may counteract the deranged lipid metabolism in the arterial wall in addition to lowering the plasma lipid levels.

\section{Acknowledgments}

We thank Ms. Misako Otabe for measuring the lipid contents of lipoproteins.

\section{References}

1) Belfrage, P. \& Vaughan, M. (1969) Simple liquid-liquid partition system for isolation of labeled oleic acid mixture with glycerides. J. Lipid Res., 10, 361-366.

2) Fielding, C.J. (1979) Validation of a procedure for exogenous isotopic labeling of lipoprotein triglyceride with radioactive triolein. Biochim. Biophys. Acta, 573, 255265.

3) Folch, J., Lees. M. \& Sloane-tanley, G.H. (1957) A simple method for isolation and purification of total lipids from animal tissues. J. Biol. Chem., 226, 497-502.

4) Kritchevsky, D. \& Kothari, H.V. (1978) Arterial enzymes of cholesterol ester metabolism. In: advances in Lipid Research, edited by R. Paoletti \& D. 
Kritchevsky, Academic Press, New York-San Francisco-London, vol. 16, 256-259.

5) Matsuoka, N., Shirai, K. \& Jackson, R.L. (1980) Preparation and properties of immobilized lipoprotein lipase. Biochim, Biophys. Acta, 620, 308-316.

6) Matsuoka, N., Shirai, K. \& Johnson, J.D. (1981) Effects of apo C-II on the lipolysis of very low density lipoproteins from apo C-II deficient patients. Metabolism, 30, 818-824.

7) Morisaki, N., Murano, S., Shinomiya, M., Sasaki, N., Shirai, K., Matsuoka, N., Mizobuchi, M., Akikusa, B., Saito, Y. \& Kumagai, A. (1982) Lipid metabolism in atherosclerotic arterial wall of rats. Atherosclerosis, 43, 51-57.

8) Nikkila, E.A. (1971) Metabolic effects of nicotinic acid and its derivatives, edited by K.F. Gey \& L.A. Carlson, Bern Hans Huber, p. 487.

9) Olsson, A.G., Orö, L. \& Rössener, S. (1974) Clinical and metabolic effects of pentaerythritol tetranicotinate (Perycit ${ }^{\circledR}$ ) and a comparison with plain nicotinic acid. Atherosclerosis, 19, 61-73.

10) Shinomiya, M., Matsuoka, N., Shirai, K., Saito, Y.\& Kumagai, A. (1979) Studies on cholesterol esterase in rat arterial wall. Atherosclerosis, 33, 343-350.

11) Sigroth, K. (1968) Pentaerythritoltetranicotinate (Perycit $\left.{ }^{\circledR}\right)$ in the treatment of hypercholesterolaemia. Acta Med. Scand., 184, 269-273.

12) Skipski, V.P., Smolowe, A.F., Sullivan, R.C. \& Barclay, H. (1965) Separation of lipid classes by thin layer chromatography. Biochim. Biophys. Acta, 106, 386-396.

13) Tall, A.R. \& Small, D.M. (1980) Body cholesterol removal : roles of plasma high density lipoproteins. Advanc. Lipid Res., 17, 1-34. 